\title{
The application of plant biotechnology in seed industry in the developing countries
}

\author{
Rajeev Taggar* \\ Green World Genetics Sdn Bhd, Malaysia
}

\begin{abstract}
The indigenous seed industry in most developing countries comprises of small and medium scale seed industry. This is supplemented by satellite research laboratories and sales \& marketing units of the large trans-national companies. From the angle of application of plant biotechnology, some of the factors playing a decisive role for the indigenous small and medium scale seed industry include quick delivery of results, readily available technologies, minimal risk in investment, proven technologies and minimal financial resources. The large scale trans-national seed companies on the other hand have the investment potential for capital-intensive research and novel research with distant returns. The academia in both, the developing and the developed countries tend to be driven more by novel research having publication potential rather than by application value. Such a situation presents the indigenous small and medium scale seed industry in the developing nations with a unique challenge of having to do with a technical work force who have a gap in training and application and to deliver with limited capital resources. This talk will cover an overview of plant biotechnology. An attempt will be made to present the actual seed industry situation in the developing countries. Plant biotechnology will be sectioned into various areas of application, of which the small and medium scale seed industry is one. The areas of strength and weakness will be discussed. With the advent of low cost sequencers, the molecular-breeding scenario is likely to change at all levels. A paradigm shift in challenges from infrastructure to analytics is expected. Discovery research versus applied research will be discussed. The clarity shed on the applications of plant biotechnology in developing countries should be a handy tool for the aspiring plant biotech professionals, seed industry in the developing countries and for the governmental policy makers.
\end{abstract}

\section{Introduction}

Plant biotechnology may be a set of techniques wont to adapt plants for specific wants or opportunities. things that mix multiple wants and opportunities square measure common. Plant Biotechnology (PBT) encompasses a large number of scientific tools and techniques for screening and genetic manipulation of plants to develop helpful or helpful plant/plant product. The proficiency of those tools and techniques may well be increased by nanotechnological interventions.

Plant biotechnologies that assist in developing new varieties and traits embrace genetic science and genetic science, MarkerAssisted Choice (MAS), and transgenic (genetic engineered) crops. These biotechnologies enable researchers to observe and map genes, discover their functions, choose for specific genes in genetic resources and breeding, and transfer genes for specific traits into plants wherever they're required. NIFA funds analysis, training, and extension for developing and exploitation biotechnologies for food and agriculture. Areas of labor embrace, however not restricted to: Genetic structures and mechanisms, Methods for transgenic biotechnology (also referred to as genetic engineering), Identification of traits and genes that may contribute to national and world goals for agriculture, Plant order sequences; molecular markers, and bioinformatics, Gene written material/Genome Editing, Synthetic Biology.

Crop improvement is that the exploitation of genetic variability, followed by many generations of choice. Breeders have continually used the foremost trendy technologies offered to them. This has allowable them to create sizable progress throughout the last twenty years, thanks specifically to the event of biotechnology. These tools allow associate acceleration of the choice method, new genetic combos that don't seem to be doable through typical breeding and bigger exactitude within the desired modifications of the order.

Making higher seed varieties has everything to try and do with higher genes. These genes square measure the codes of instruction found in each animate thing - codes that tell organisms to create substances for growth, survival and plenty of different functions or traits. Plant biotechnology has enabled researchers to require helpful genes from hand-picked organisms and introduce them into plants, so creating higher varieties. Some examples embrace biotechnology crops that square measure immune to pests, additional wholesome, or contribute to finish product of different industries, like biofuels

Biological management agents used as seed treatments square measure microorganisms that defend seeds and seedlings from numerous pathogens. Of the biological management agents proprietary by early 1999, eighty four were microorganism (mainly Pseudomonas spp. and Bacillus spp.) and 16 PF were fungi. The mode of action of biological management agents is classified as antagonism, antibiosis, competition or mycoparasitism. These agents might offer an honest answer for cover against specific pathogens, specifically within the case of organic farming. Cotton has been the primary large-scale scientific discipline crop treated with biological management agents for the suppression of Phanerogam diseases of the rhizosphere and, today a lot of the cotton planted within the USA is treated with such agents. 
These product have additionally been used and tested on many different agricultural and vegetable crops (STEC, 2000).

Limited understanding of rhizosphere ecology, formulation difficulties, storage and stability issues when application to the seed, and un harness of some product that typically failed to meet performance expectations, have caught up the expansion and adoption of the technology. Moreover, restrictive problems, like registration and discard problems, might represent constraints to the event and use of such product. Today, they're being actively developed by variety of firms. If the investment during this technology continues at this pace, this product can in all probability have a major place within the choices to shield seed and seedlings. the role of biotechnological tools like micropropagation, molecular markers, reproductive structure culture, cybridization, elicited male sterility and transgenic within the production of specific parental lines or hybrids in vegetables. Micropropagation is used for maintenance of male sterile lines either controlled by recessive genes (tomato, muskmelon, chilli) or dominant genes (cabbage); maintenance of self-incompatible lines in cole crops and maintenance of hybrids per se through tissue culture.

\section{Conclusion}

Biotechnological tools have greatly contributed to the assembly and provide of improved quality seed and planting material to farmers worldwide. Among different uses, biotechnology is used to speed-up the multiplication method for vegetatively propagated crops, detect diseases transmitted by seed or planting material, eradicate diseases transmitted by planting material, protect seed with biological management agents and check varietal identity and purity.

\section{Biography}

Rajeev Taggar has been associated with biotechnology in the seed industry for about 20 years. As a Scientist In-charge of Molecular Breeding activities, he worked with Bayer CropScience, India, Krishidhan Seeds, India, ICRISAT, India and Green World Genetics Sdn Bhd, Malaysia (Presently working). Working closely with a team of crop breeders, he established molecular breeding laboratories and molecular breeding programmes for his employer organizations. He got professional training in Plant Biotechnological techniques from Germany on a DSE-sponsored course, from the Central Research Facility of Nunhems Zaden, the Netherlands and from the John Innes Centre (UK). He holds an MSc in Plant Genetics \& Crop Improvement from John Innes Centre, University of East Anglia, UK; MSc in Botany and MPhil (Botany) from Kurukshetra University, India.

\section{References}

1. RK Taggar. Democratizing plant biotechnology: the case of seed industry. J Microbiol Biotechnol Rep 1(1):14-16.

\section{*Correspondence to:}

Rajeev Taggar

Green World Genetics Sdn Bhd

Malaysia

E-mail: rajeevtaggar@hotmail.com 